\title{
GIS
}

Dol

dx.doi.org/10.11606/issn.2525-

3123.gis. 2020.163412

\section{BÁRBARA COPQUE}

Universidade do Estado do Rio de Janeiro, Rio de Janeiro,

orcid.org/0000-0002-5258-1439

RJ, Brasil, 20550-900 - defp.febf.uerj@gmail.com
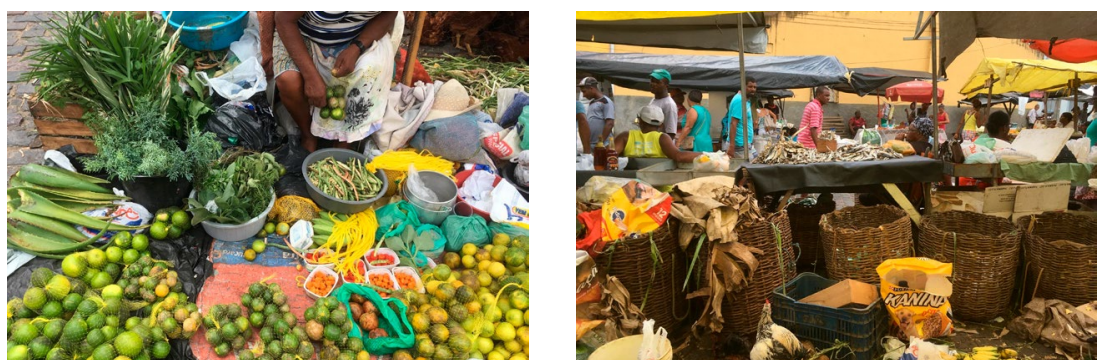

\section{ACOUGUE'SÄO FRANGISCO}
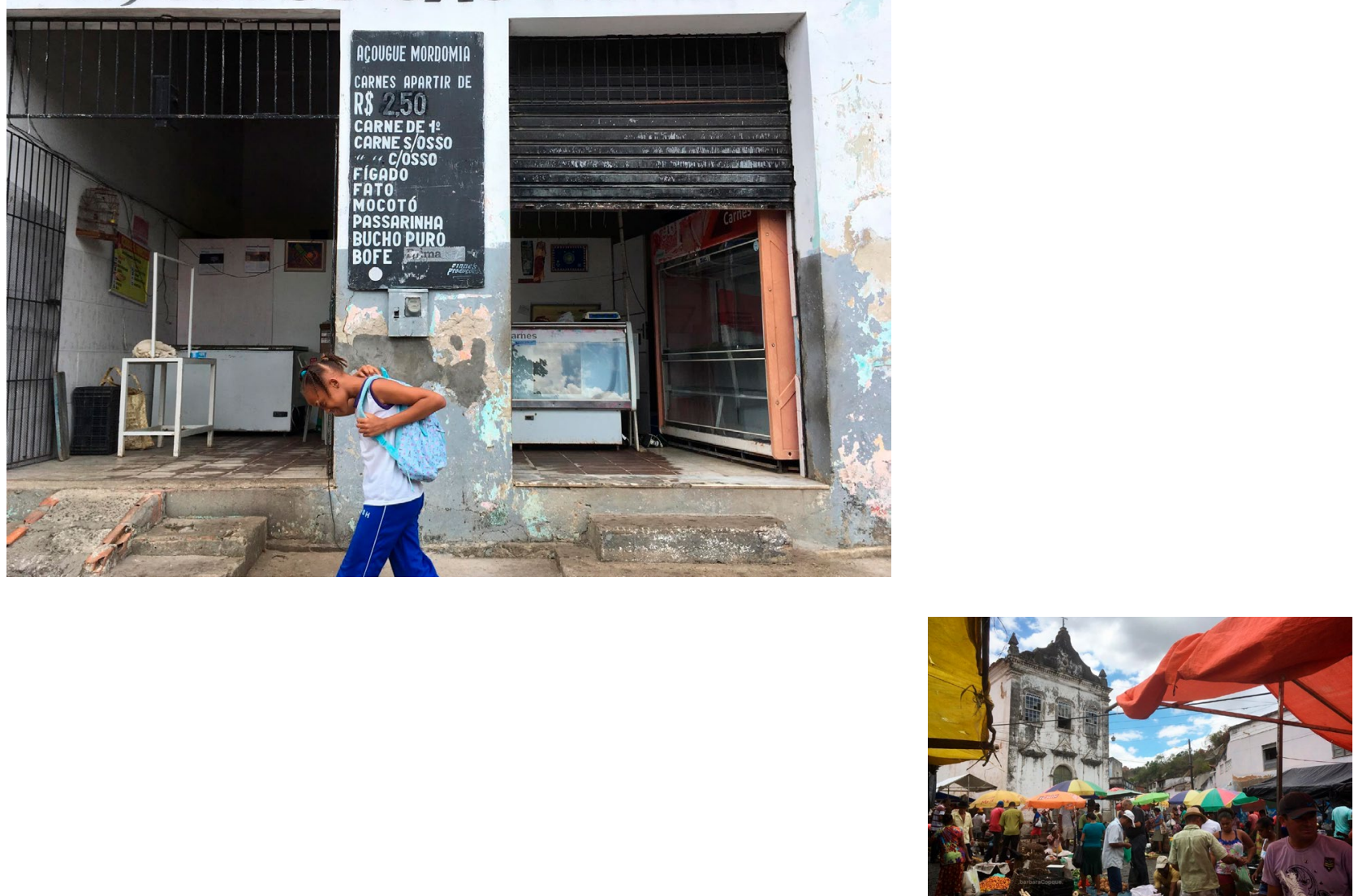
As mulheres da minha família sempre se relacionaram com o tempo. Quando pequena, ouvia da minha avó materna: "o tempo dá, o tempo tira, o tempo passa e a folha vira!". E da minha mãe, Luiza: "o tempo é que cura o fumo!". Esse tempo, tão presente na minha vida, sempre foi um pouco diferente: em casa, o vivíamos como se fôssemos aparentados; ele era uma árvore, uma entidade, um Orixá. E o reconhecíamos por Irôko, a primeira árvore, aquela que liga o céu à terra e pela qual todos os Orixás desceram ao nosso mundo. Irôko era uma das imagens que me faltavam, um dos meus assentamentos.

Em 2018, resolvi ir atrás desse meu enredo e, na companhia de minha mãe, vivenciar fotograficamente esse tempo. Quem nasce no Recôncavo tem sua vida enredada pelos terreiros, e nesses espaços o enredo refere-se não só à história de vida de alguém como a um conjunto emaranhado (Ingold 2012) de relações entre os humanos e os orixás. Ter enredo equivale ser, de certa forma, o Orixá e o outro, carregando consigo um pouco de cada um. Assim, rever o Irôko é recordar conjuntamente algumas imagens com os fios narrativos de minha mãe e de minha avó Dete. Seguimos, então, para Santo Amaro da Purificação, Acupe, Saubara, Cachoeira, Santo Estêvão, Suape e Madre de Deus, cidades localizadas no Recôncavo Baiano e que guardam nossa ancestralidade.

Há 130 anos, no Largo do Mercado de Santo Amaro da Purificação, é montado um barracão onde acontece o Bembé do Mercado', uma manifestação de xirế2. Nele, durante os três dias que precedem o 13 de maio, a comunidade de terreiro - das mais importantes e antigas, de várias nações e adjacências, bem como de terreiros de Salvador - toca o dia inteiro, rememorando a extinção legal da escravidão e reafirmando a identidade afrodescendente. Em junho de 1958, a festa ganhou uma dimensão religiosa após enchentes na cidade e uma violenta explosão de fogos que incendiou o mercado. Fala a tradição santamarense que, se não há toque, a cidade vive momentos de catástrofe. Tal incidente ardeu na minha família. Entre as centenas de mortos, minha mãe encontrou o meu tio, que "carregava o número 99 dos irreconhecíveis". Este acontecimento trouxe a depressão, a loucura e muitas dificuldades aos meus familiares. Percorrendo a consumação dessas lembranças no mercado de Santo Amaro, vali-me da companhia de Didi-Huberman (2012), que com suas palavras dava-me alento para pensar a condição lacunar e residual das imagens, como cinzas de tudo aquilo que me ardeu. Neste ensaio, trago algumas imagens que me faltavam ${ }^{3}$.

1. A festa foi considerada Patrimônio Imaterial da Bahia no Registro Especial dos Eventos e Celebrações, pelo Decreto $n^{\circ} 14.129 / 2012$.

2. Ritual público de caráter festivo de culto aos Orixás.

3. Parte integrante de um ensaio em processo. 


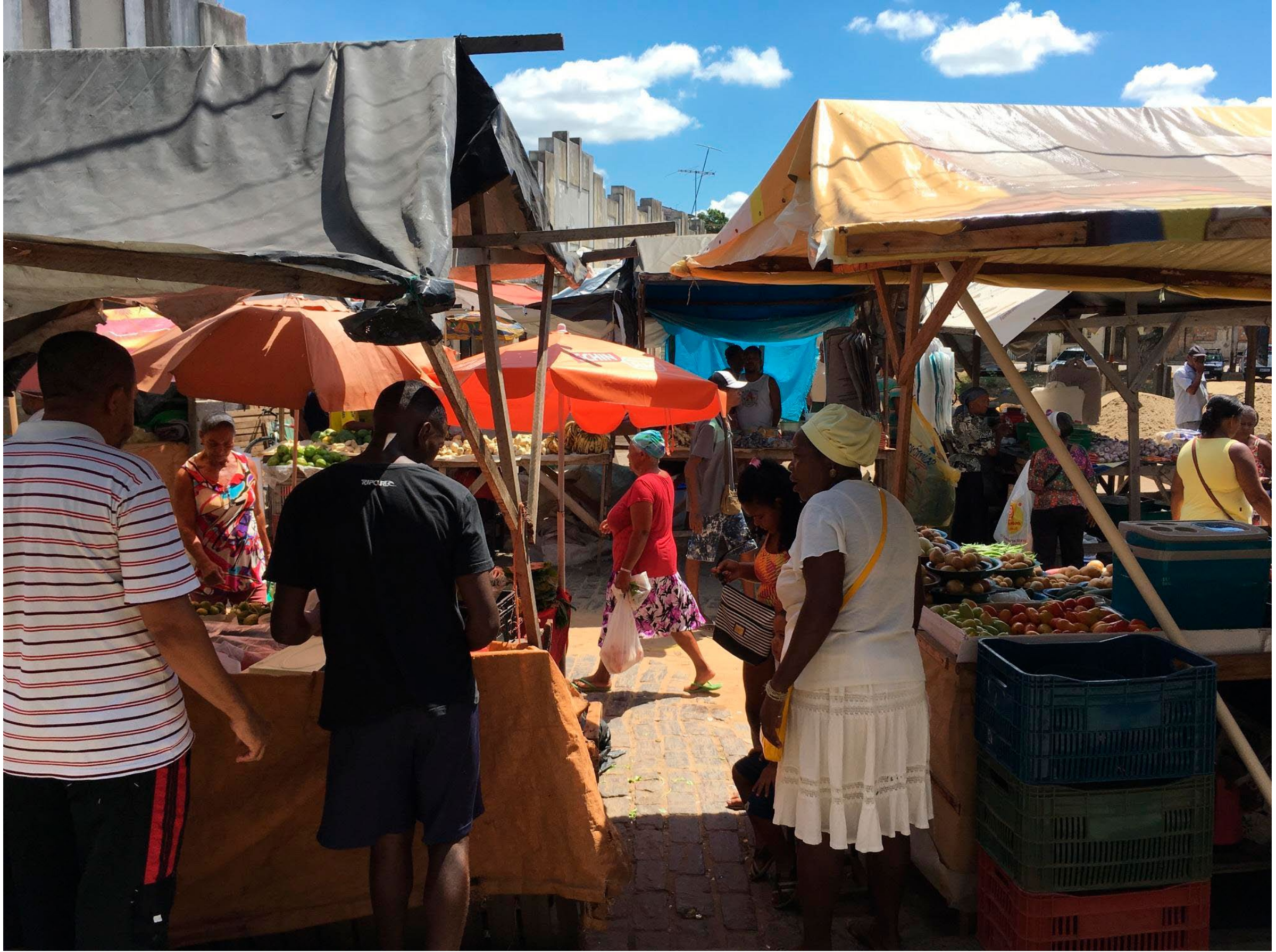




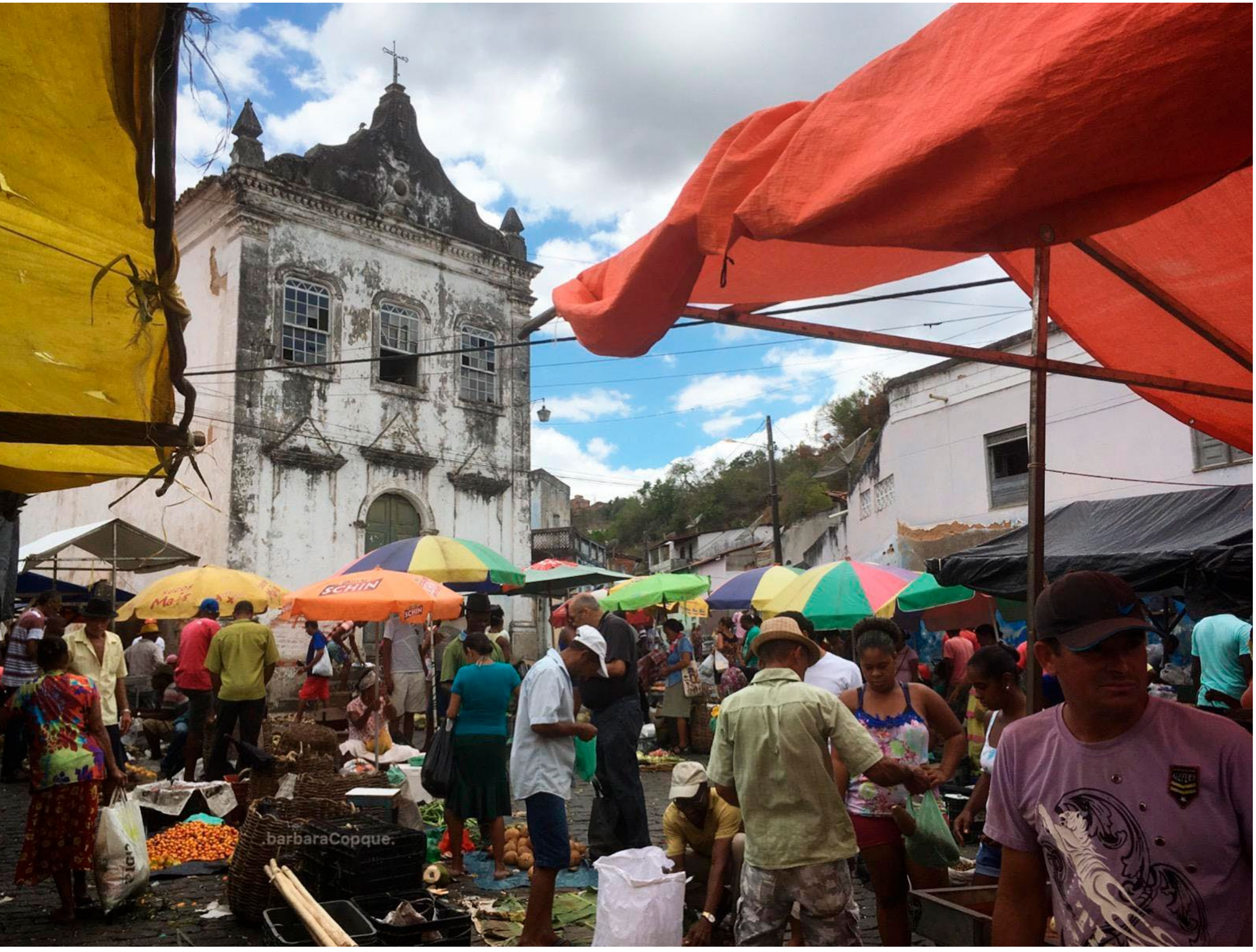




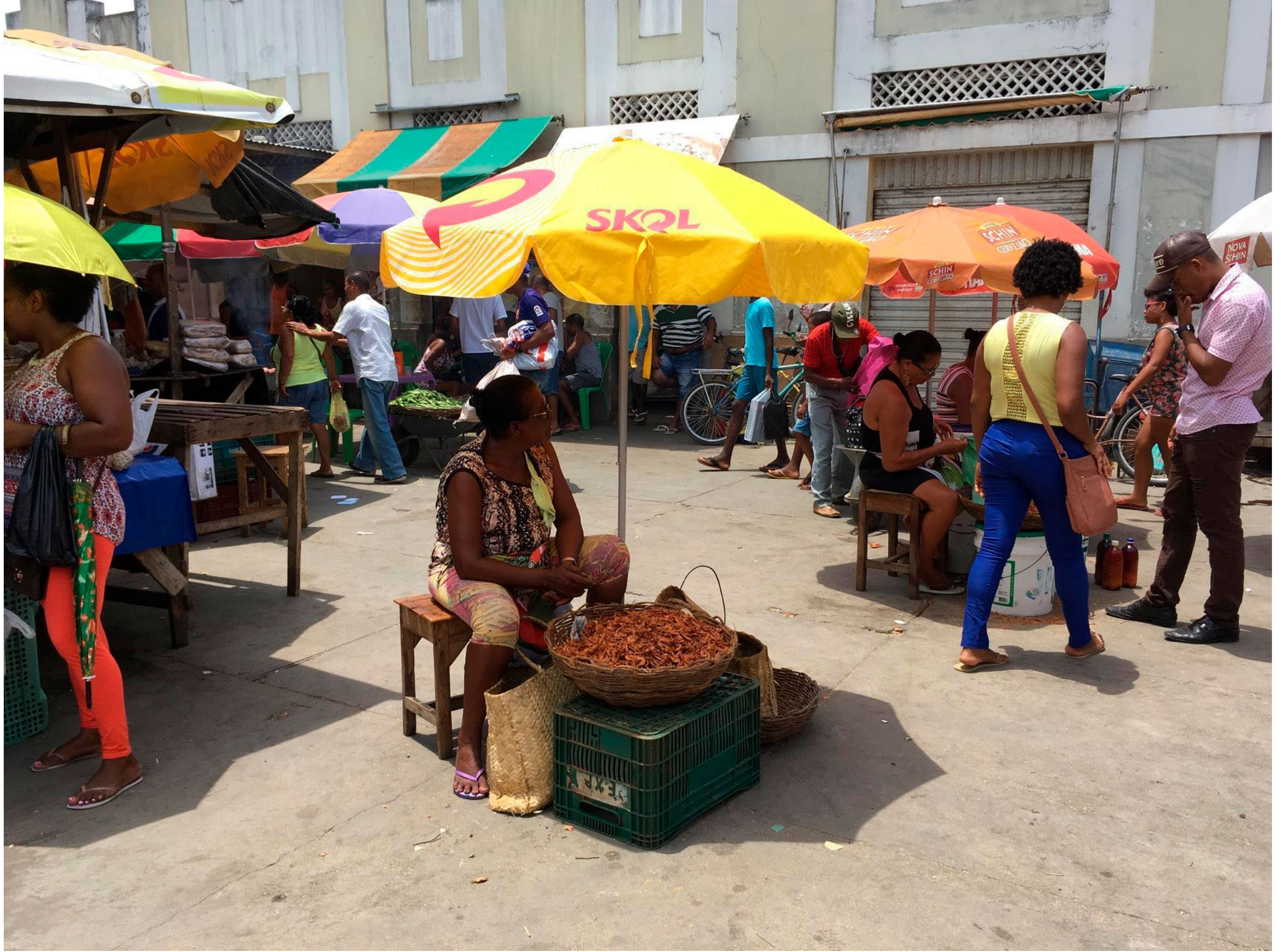




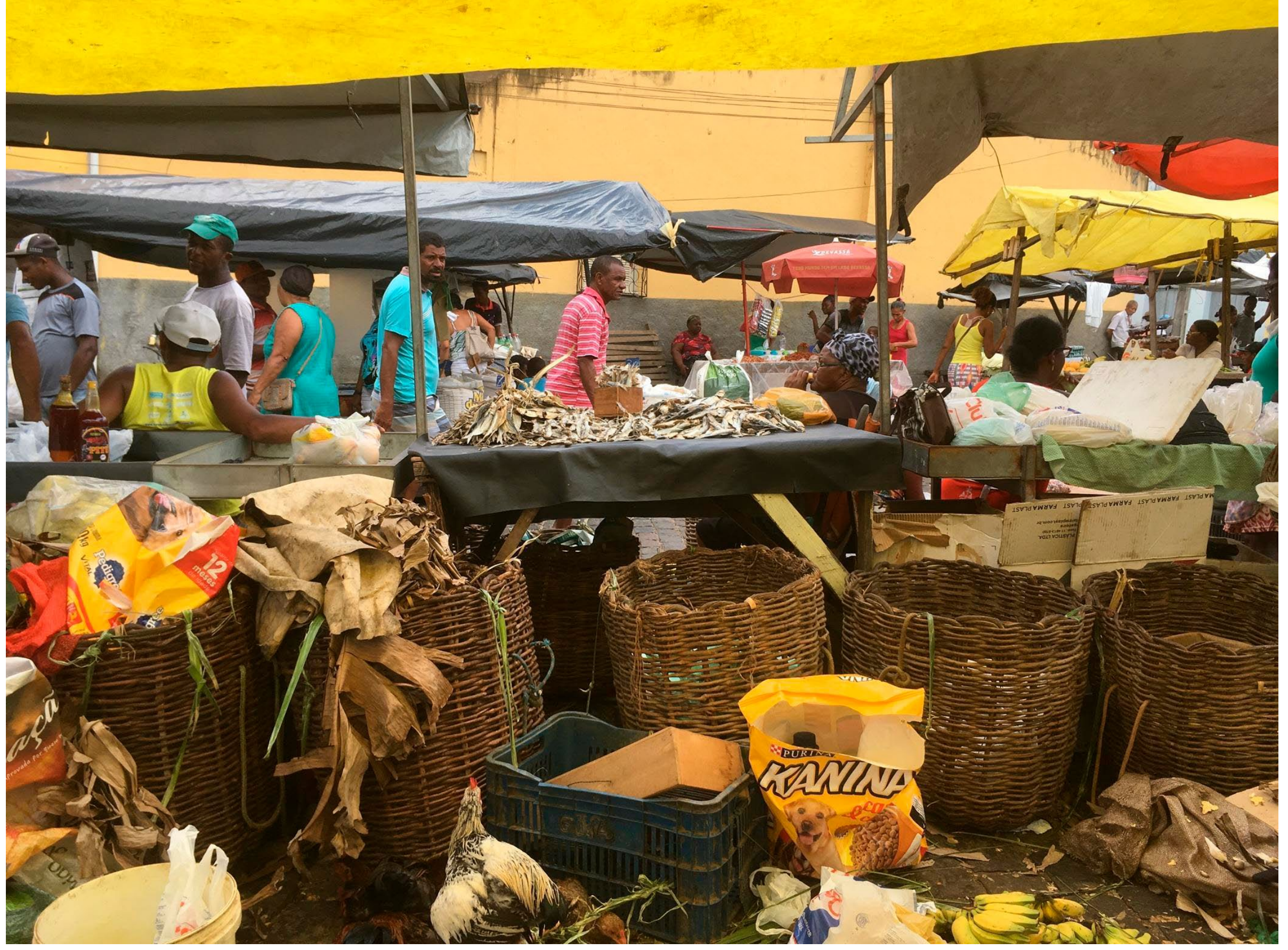


7 GÊNEROS ALIMENTÍCIOS

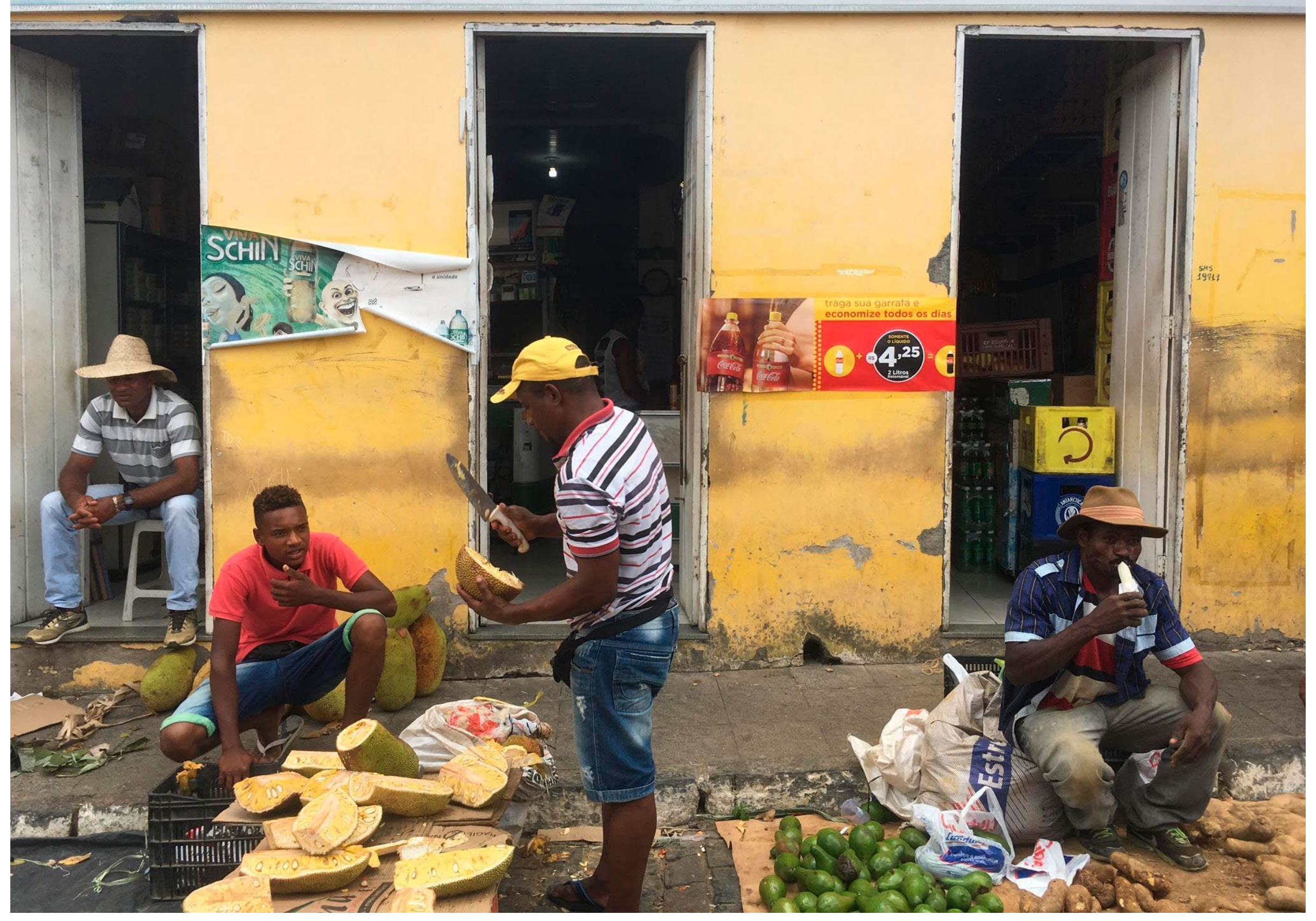




\section{ACOUGUE SÁO FRANGISCO}

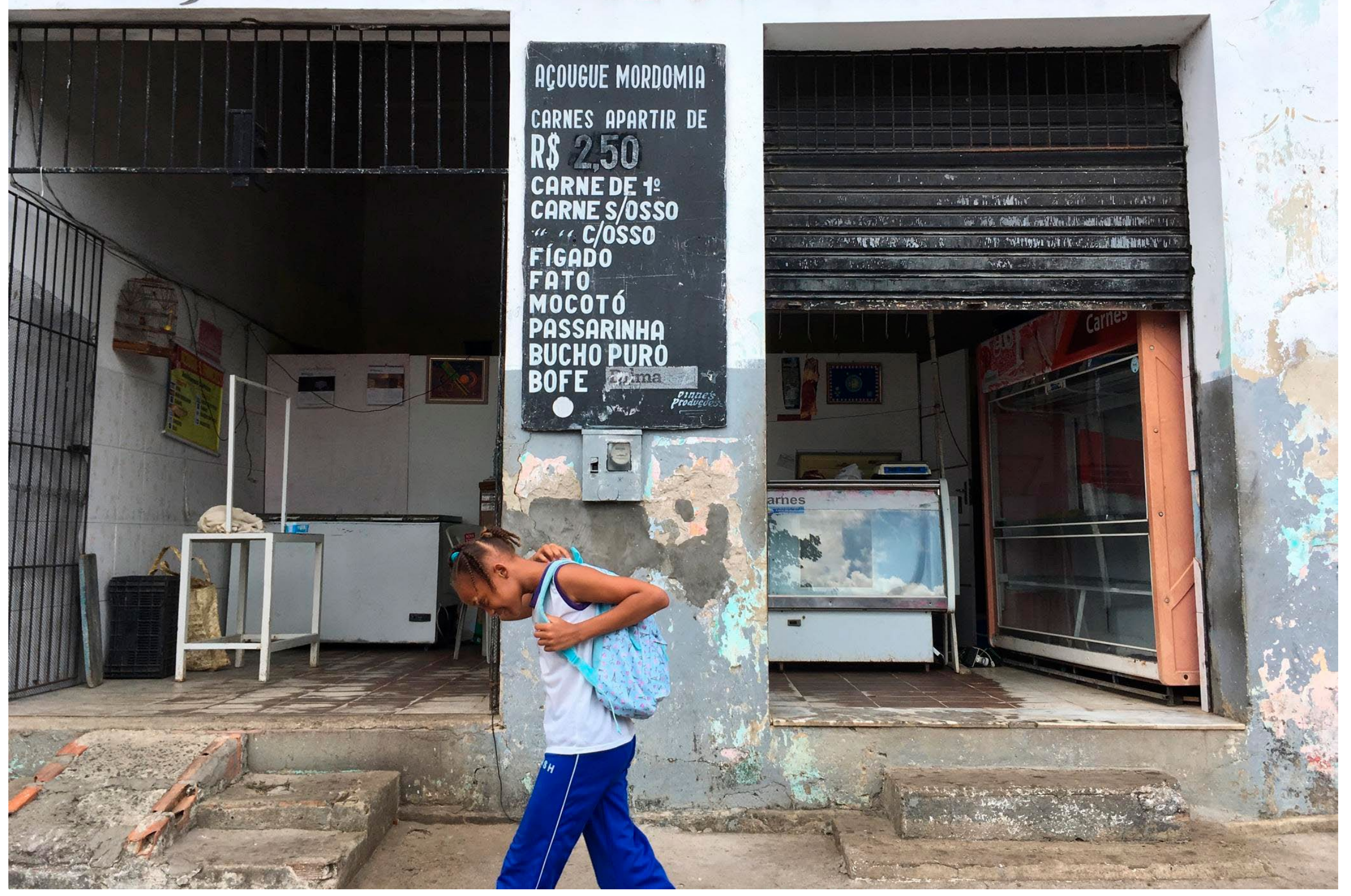




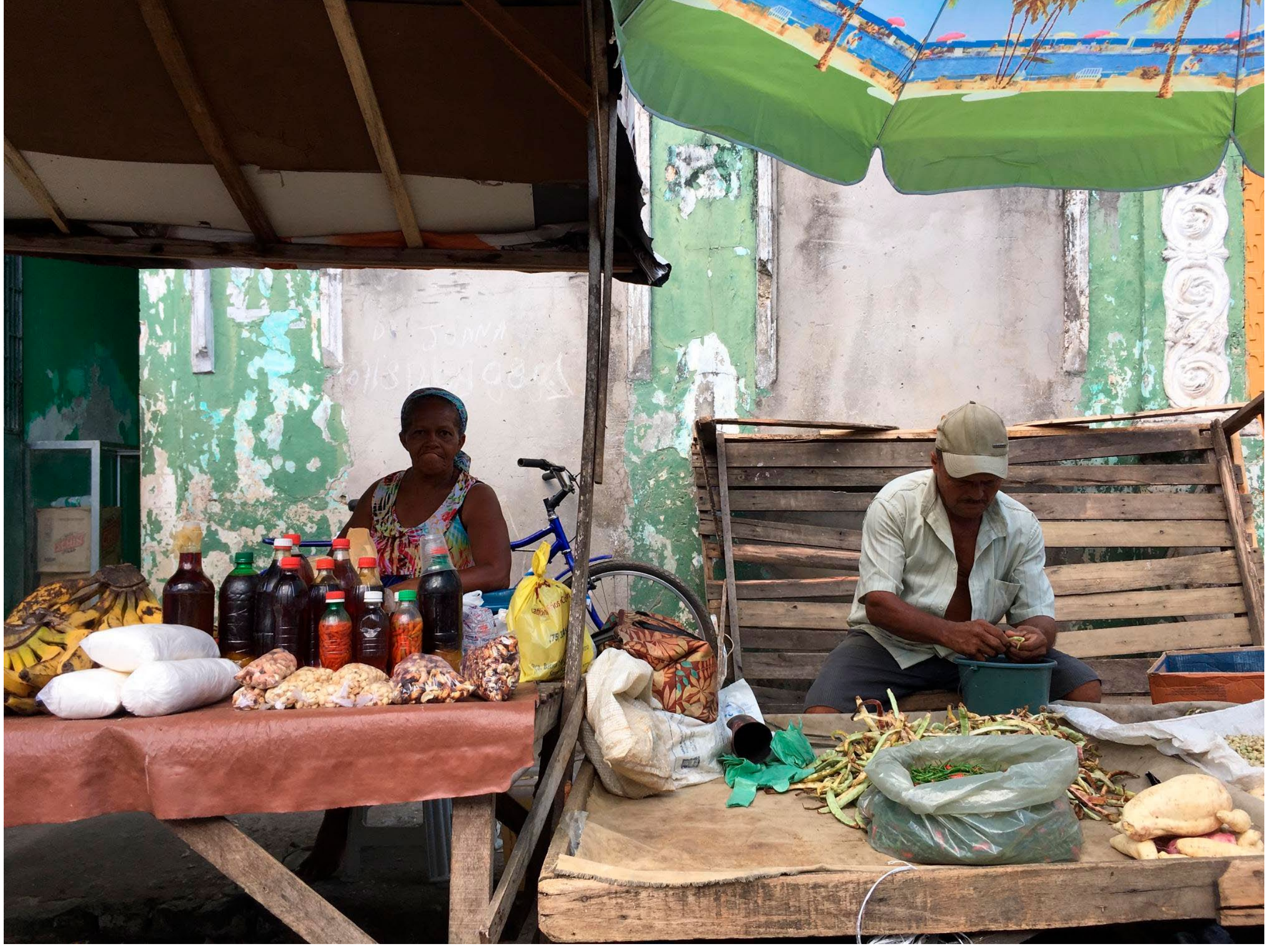









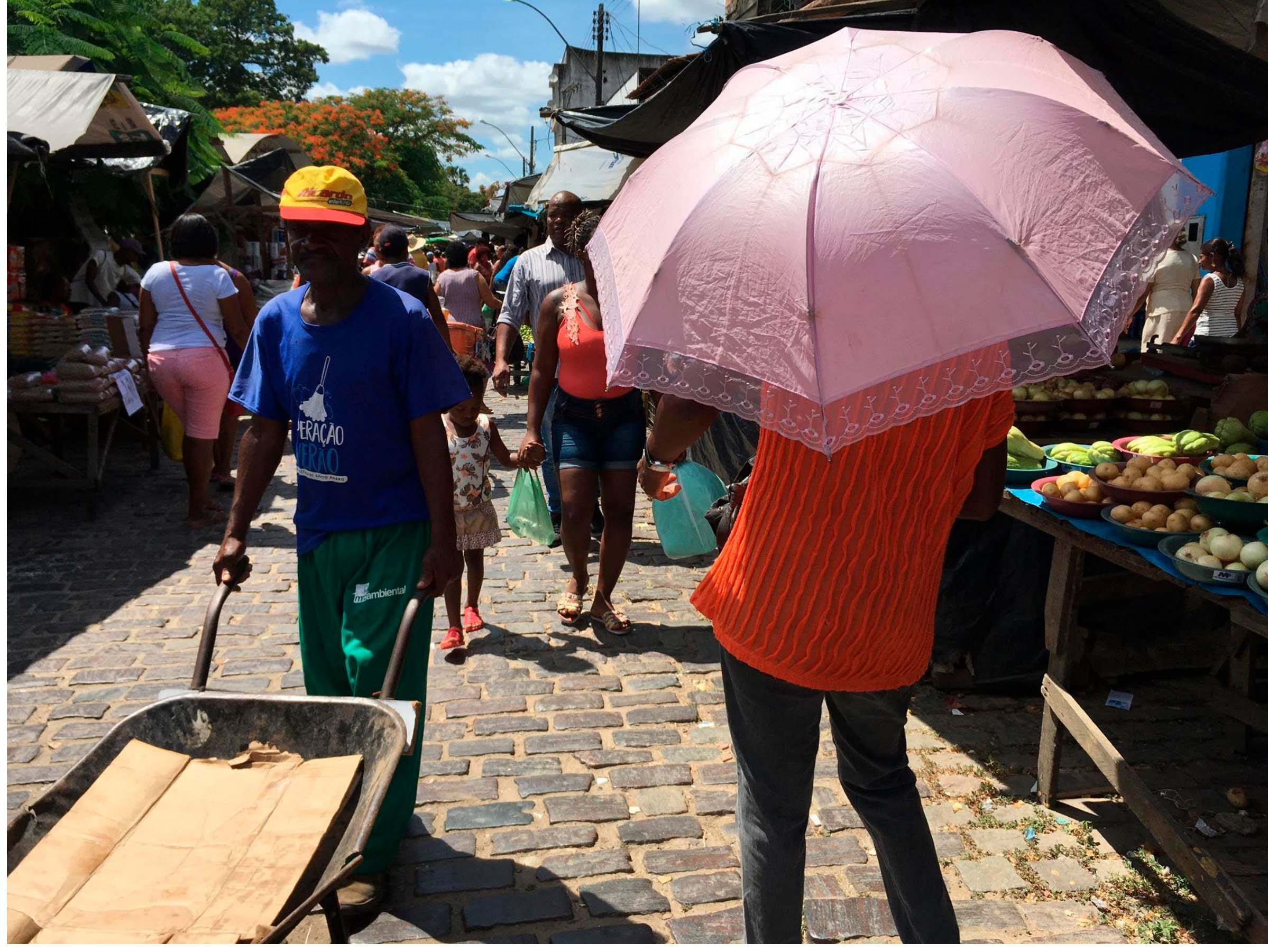




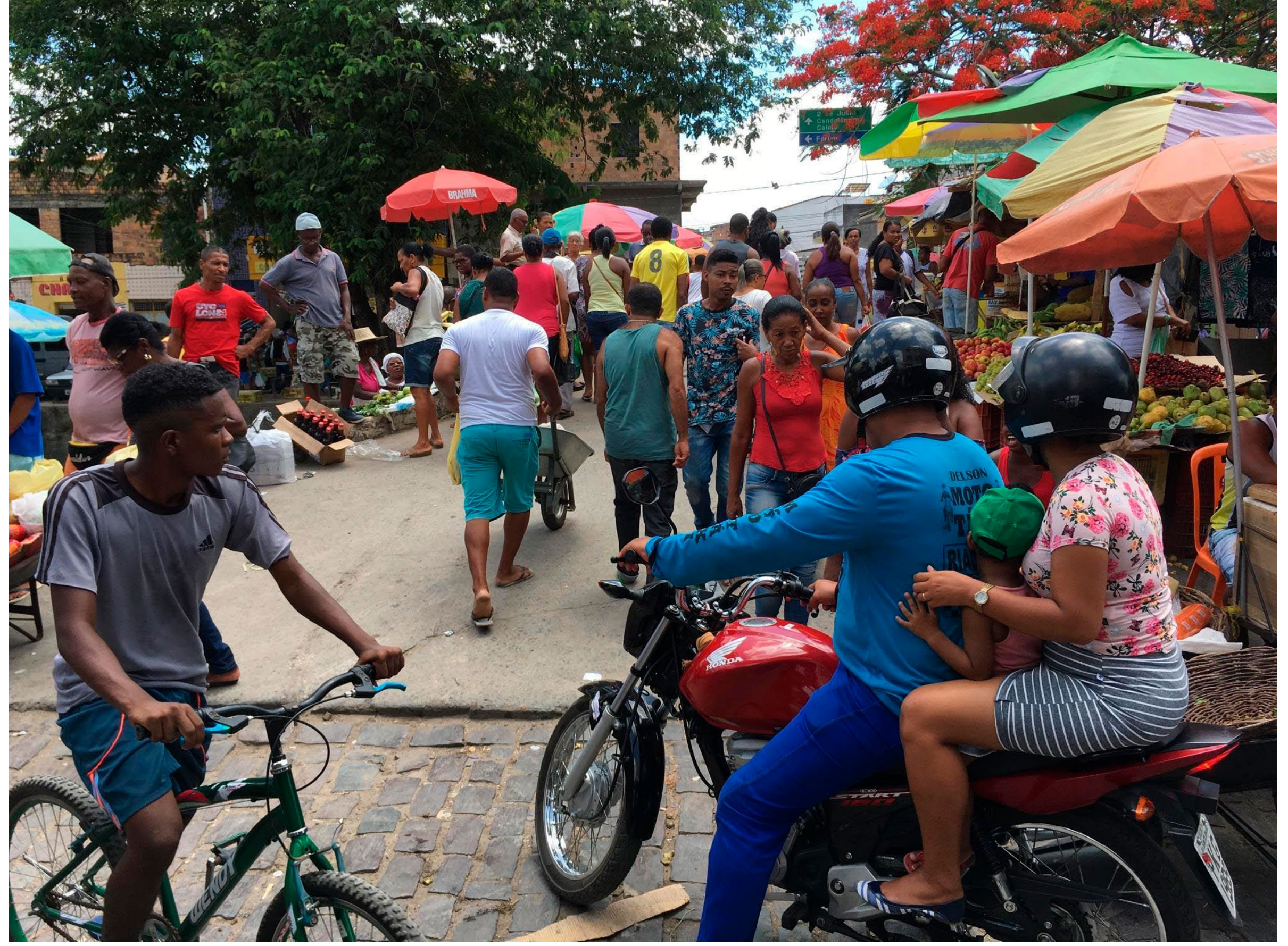




\section{REFERÊNCIAS BIBLIOGRÁFICAS}

Didi-Huberman, Georges. 2012. Quando as imagens tocam o real. Revista Pós, vol. 2, $n^{\circ} .4: 206-219$.

Flaksman, Clara. 2017. Enredo de santo e sincretismos no candomblé de Salvador, Bahia. Revista de Antropologia da UFSCar, vol. 9, n. 2: 153-169.

Ingold, Tim. 2012. Trazendo as coisas de volta à vida: emaranhados criativos num mundo de materiais. Horizontes Antropológicos, vol. 18, nº. 37: 25-44.

PALAVRAS-CHAVE

Antropologia visual; fotografia; memória; ancestralidade; sankofa.

KEYWORDS Visual anthropology; photography; memory; ancestrality; Sankofa.

\section{RESUMO}

No presente ensaio me proponho a vivenciar fotograficamente as minhas memórias e dar forma às lembranças compartilhadas pela minha mãe, me colocando numa atividade de imaginação durante uma viagem no Recôncavo Baiano, terra da nossa ancestralidade.

\section{ABSTRACT}

In this essay, I propose to give form to my mother's shared remembering as well as to experience my own memories with photography by putting myself into an activity of imagination during a trip to the Recôncavo Baiano, land of our ancestrality.

BÁRBARA COPQUE é doutora em Ciências Sociais pela Universidade do Estado do Rio de Janeiro (Uerj) e professora adjunta da Faculdade de Educação da Baixada Fluminense (FEBF/Uerj). Coordenou o Grupo de Pesquisa Imagens, Narrativas e Práticas Sociais (Inarra) (CNPq-Uerj) e, atualmente, é coordenadora do Núcleo de Estudos Visuais em Periferias Urbanas (NuVISU) (CNPq-Uerj) e integrante do coletivo de artes visuais Negras[fotos]grafias. E-mail: barbara.copque@gmail.com 